\title{
Learning from malpractice claims about negligent, adverse events in primary care in the United States
}

\author{
R L Phillips Jr, L A Bartholomew, S M Dovey, G E Fryer Jr, T J Miyoshi, L A Green
}

See editorial commentary, p 90

Qual Saf Health Care 2004;13:121-126. doi: 10.1136/qshc.2003.008029

See end of article for authors' affiliations

.....................

Correspondence to: Dr R L Phillips Jr,

The Robert Graham

Center: Policy Studies in

Family Practice and

Primary Care, 1350

Connecticut Avenue NW

Suite 201, Washington,

DC 20036, USA;

bphillips@aafp.org

Accepted

19 December 2003

Background: The epidemiology, risks, and outcomes of errors in primary care are poorly understood. Malpractice claims brought for negligent adverse events offer a useful insight into errors in primary care. Methods: Physician Insurers Association of America malpractice claims data (1985-2000) were analyzed for proportions of negligent claims by primary care specialty, setting, severity, health condition, and attributed cause. We also calculated risks of a claim for condition-specific negligent events relative to the prevalence of those conditions in primary care.

Results: Of 49345 primary care claims, 26126 (53\%) were peer reviewed and 5921 (23\%) were assessed as negligent; $68 \%$ of claims were for negligent events in outpatient settings. No single condition accounted for more than $5 \%$ of all negligent claims, but the underlying causes were more clustered with "diagnosis error" making up one third of claims. The ratios of condition-specific negligent event claims relative to the frequency of those conditions in primary care revealed a significantly disproportionate risk for a number of conditions (for example, appendicitis was 25 times more likely to generate a claim for negligence than breast cancer).

Conclusions: Claims data identify conditions and processes where primary health care in the United States is prone to go awry. The burden of severe outcomes and death from malpractice claims made against primary care physicians was greater in primary care outpatient settings than in hospitals. Although these data enhance information about error related negligent events in primary care, particularly when combined with other primary care data, there are many operating limitations.

$\mathrm{S}$ everal organizations have called attention to the deficiency of patient safety research in primary and ambulatory care. ${ }^{1-3}$ This healthcare setting should not be exempt from scrutiny for medical errors. It is a potentially high risk environment because of the increasing complexity of care provided in outpatient settings and the risk created by dysfunctional interfaces between inpatient and outpatient (particularly primary) care. There is a perception that, even if more errors occur in primary outpatient care than in hospitals, they are unlikely to result in significant harm to patients. $^{34}$ The few existing studies of patient safety in primary care suggest that this notion underestimates the combined effects of patient volume, complexity, and repetitive systematic errors. ${ }^{5-9}$ In addition, studies of physicianrecognized errors in primary care suggest that errors occur frequently and that seemingly trivial mistakes can result in severe harm, particularly for vulnerable patient populations. $^{5610}$

Recent studies of medical errors in primary care have helped develop reporting systems and preliminary error taxonomies, but they have been small, have relied on physicians' reports, and may not be generalizable to all primary care physicians in the US or other countries as they have been mainly by family physicians and general practice doctors, excluding general internists and pediatricians who also provide primary health care in the US..$^{5-7}$ To address these limitations and to explore other data that might reveal important features and patterns of incidents and injuries in primary care, we studied malpractice databases of the Physician Insurers Association of America (PIAA). The PIAA is an organization of 52 medical insurance companies whose members insure over 250000 physicians, 23000 dentists, and 1200 hospitals in the US and over 400000 healthcare workers worldwide. PIAA data are analyzed regularly for member organizations to identify claim trends and improve care (http://www.thepiaa.org/publications/ datareport.htm), and have been studied to find ways to improve diabetes care. ${ }^{11}$ Error related claims from a single state based insurer have also been used to identify clinical processes prone to problems in four medical specialties and to study medication related adverse outcomes. ${ }^{12}{ }^{13}$

Common legal principles for medical negligence apply in the US and the UK, and both countries also share problems with how these principles are applied. ${ }^{14}$ In both countries a patient must show that a doctor, who owed a duty of care, was in breach of that duty of care and that the breach was causative of a reasonably foreseeable harm. In England, whether a breach has occurred is determined by assessing practice against what a "reasonable body of medical men skilled in that particular art" would do. In the US determination is based on the standard of care for a peer in the same specialty in a similar community. The two countries also share a common experience with rising numbers and costs of claims for medical negligence. In 2000 there were just over 16000 paid claims against medical healthcare providers in the US with total payments of nearly \$4 billion..$^{15}$ In 1999 the NHS Litigation Authority closed 3254 claims at a cost of £386 million. ${ }^{16}$ Beyond the context of safety, we also anticipated that this analysis might provide evidence for prioritizing efforts to improve quality and reduce costs in both the US and UK.

This study aimed to describe the epidemiology of negligent adverse events from primary care PIAA data, including where these events occurred, the conditions they affected, and the attributed root causes of the resulting claims. Our second aim was to assess the rates of claims for condition-specific negligent events relative to rates of office visits for those same conditions in primary care. Malpractice litigation for overtly negligent events is likely to be more specific than sensitive for errors that occur in health care. However, the process and claims reflect errors that are recognized by the people they affect, and those people bring their claim not only 
seeking justice but to prevent others from being exposed to the same error. ${ }^{17}$ Settled claims for negligent adverse events are an expression of patients' experiences of medical errors causing harm and their desire to prevent them from happening again. For these reasons, they provide a useful insight into errors in primary care.

\section{METHODS \\ Databases}

We analyzed 49345 claims settled between 1985 and 2000 involving primary care physicians (family physicians and general practitioners (FP/GPs), general internists, and general pediatricians). Since 1985 many domestic insurance company members of the PIAA have participated in a data sharing project. At the present time there are 14 participating companies reporting about 7500 claims annually, down from a high in the mid 1990s of about 14000 annual claims reported by 23 companies. Data in this study represent a total of 361 member years and a total of 1834242 exposure years (one physician insured for one year) represented over the history of this project. The goal of the data sharing project is to provide member companies with detailed and credible data to inform risk management programs striving to reduce the incidence of patient injury, and subsequent physician exposure to claims. From 1985 to 2000 member companies had reported 156000 claims and suits with over 41000 paid claims. ${ }^{18}$

\section{Definitions}

- Suit or claim: a suit is any written demand for compensation in the form of money or services, with no legal papers having been filed in court. A claim is formal litigation that alleges an error or omission on the part of one or more defendants, and demands compensation by money or services to claimants. For our analyses we combined suits and claims as "claims".

- Negligent claims: peer reviewed claims judged to involve medical negligence and to be "indefensible".

- Non-negligent adverse event claims: peer reviewed claims for perceived or actual bad outcomes judged to be "defensible".

- Other claims: claims for which reviewers had insufficient or conflicting evidence of defensibility.

- Underlying cause: the earliest and/or most significant contributing cause of a claim is designated by PIAA as a "medical misadventure". We renamed these "underlying causes".

- Contributing factors: factors contributing to an incident could be reported for each case. These are typically factors that would not have led to the event independently, but contributed to the effect of the underlying cause.

- Outcome measure: the severity of the incident or injury, categorized as low, moderate, high, or death.

\section{Explanation of definitions}

Determinations of negligence were based on peer reviews. Many PIAA member companies have physician peer reviewers or review panels that review filed claims. The review panels that determine company liability decisions comprise physicians, one of whom must be the same specialty as the defendant. Peer reviewers have access to the full claim record. The standard of care, professional and patient culpability, and any other circumstances are taken into account. If a physician defendant disagrees with a peer reviewer's decision, the full committee will review a claim and reach a consensus. Most companies go through this liability decision process but not all companies report decisions to the data sharing project. In the interest of saving resources, some companies report only required fields to the PIAA and the field representing the defensibility decision is optional. If a case is not defensible, this exercise provides a consistent way to explain to physicians why cases should be settled. PIAA companies' review guidelines are clear-if a defendant doctor meets the standard of care and there are no alterations or blatant omissions in the medical record or communications failures, the company will decide to defend. PIAA found that $87 \%$ of "defensible" claims prevail in court and $93 \%$ of all closed "defensible" claims are settled in favor of the defendant.

We renamed medical misadventures "underlying causes" because the process is about selecting a proximal cause for a claim by directing coders to ask: "If this event alone occurred, would the patient have filed suit?" and "Had the other events not occurred, would the presence of this event still have resulted in a suit?" Eighteen medical misadventure codes are used to classify underlying causes (box 1). Reviewers may also indicate that no medical misadventure could be identified.

For the outcome measure we combined the nine categories of injury assigned by PIAA companies and adopted from the National Association of Insurance Commissioners into four categories: low severity (emotional injury, insignificant injury, or minor temporary injury); moderate severity (major temporary or minor permanent injury); high severity (significant permanent, major permanent, or grave injury); and death.

\section{Statistical analysis}

Frequencies of claims by outcome severity were calculated by event location and by specialty, and Pearson's $\chi^{2}$ test was used to assess differences in severity categories for event location. Claims were grouped by whether they had been assessed by a review panel and were then further subdivided into negligent adverse events, non-negligent adverse events, and other. We assessed most common medical conditions seen in primary care practices and underlying causes for negligent adverse events. Contributing factors were assessed for frequency of association with outcome severity categories.

\section{Box 1 Categories for underlying cause of} malpractice claim

- Diagnosis error

- Wrong patient or body part

- Medication errors

- Improper performance

- Failure to instruct or communicate with patient

- Performed when not indicated or contraindicated

- Delay in performance

- Not performed

- Surgical foreign body left in patient after procedure

- Patient positioning problem

- Failure to supervise or monitor case

- Failure to recognize a complication of treatment

- Not or improperly performing resuscitation

- Failure/delay in admission to hospital

- Failure/delay in referral or consultation

- Improper supervision of resident or other staff personnel

- Failure to properly respond

- Surgical/procedural clearance contraindicated

- No medical misadventure 
Incident dates for claims in the reviewed and non-reviewed categories were also analyzed to see if there was evidence of a temporal difference that might suggest a bias; analysis of variance was used to assess differences.

The proportions of negligent adverse events for specific medical conditions were calculated from PIAA data and the proportions of total office visits to primary care physicians for treatment of these conditions were calculated using weighted data from all 14 National Ambulatory Medical Care Surveys (NAMCS) conducted since 1980. We chose to use aggregate NAMCS data rather than a single year as they better reflect the time span over which these claims were generated. We also chose to apply weights to the NAMCS data to better reflect the experiences of the US population. The ratio of the proportion of negligent adverse events for a given condition and the proportion of office visits for the same condition was used to assess the relative risk of a negligent adverse event occurring and resulting in a claim. The National Center for Health Statistics does not currently have standard error estimates for weighted NAMCS data before 1993 so we are unable to calculate standard errors or confidence intervals for the risk ratios. We believe confidence intervals would be quite significant given that these aggregated weighted data represent more than five billion office visits, and recent studies using a decade of NAMCS data in a similar fashion produced robust significant confidence intervals. ${ }^{19}$ Information on NAMCS survey methodology is available from the National Center for Health Statistics (http://www.cdc.gov/nchs).

The study protocol was approved by the Georgetown University Medical Institutional Review Board.

\section{RESULTS}

Negligent adverse events

Just over half of closed claims were reported as having been reviewed for negligence (53\%, fig 1). Reviewed claims were slightly more likely to result in an indemnity payment and this was statistically significant $\left(30 \% \vee 26 \%, \chi^{2}=89.8\right.$, $\mathrm{p}<0.001)$. Dates for claim incidence were not normally distributed and analysis of variance revealed that the difference in the date of incidence for reviewed $v$ nonreviewed claims was significant (median 11 January 1987 for reviewed $v 8$ January 1989 for non-reviewed, $\mathrm{F}=1.480$, $\mathrm{p}<0.001$ ), but not enough to suggest a temporal bias. Of the reviewed claims, 5921 (23\%) were judged to be negligent and these claims are the focus of our study.

\section{Outcome severity}

Negligent adverse event claims involving general internists $(\mathrm{n}=2751)$ and FP/GPs $(\mathrm{n}=2600)$ were more common than claims against general pediatricians $(n=570$, fig 2$) .68 \%$ of all primary care claims were related to events occurring in outpatient settings. A higher proportion of claims arising from inpatient care resulted in severe outcomes $(22.7 \%$ inpatient $v 17.6 \%$ outpatient, $\mathrm{p}<0.001)$ and death $(48.6 \%$ inpatient $v 30.6 \%$ outpatient, $\mathrm{p}=0.006$ ).

\section{Conditions and causes associated with negligent and non-negligent adverse events}

The 10 most common medical conditions associated with negligent adverse events comprised $21 \%$ of claims, and the most prominent was acute myocardial infarction (5\%,

\begin{tabular}{|lc|}
\hline \multicolumn{2}{|c|}{ Total primary care claims $(\mathrm{N}=49345)$} \\
\hline Number with payment: & $13935(28 \%)$ \\
\hline Number without payment: & $35410(72 \%)$ \\
\hline Total paid: $\$ 2.2$ billion indemnity, $\$ 740$ million expenses \\
\hline
\end{tabular}

\begin{tabular}{|c|c|c|c|c|c|c|c|c|}
\hline & & & & & & & & \\
\hline Expert pan & review & $d$ cases $(N$ & $26126(53 \%$ & & Non-reviev & wed cases ( & $=2321$ & $(47 \%))$ \\
\hline Payme & to clai & ant $(N=78$ & $1(30 \%)) \S$ & & Payment to & o claimant (I & $=6084$ & $6 \%) \S \S$ \\
\hline $\begin{array}{l}\text { Incident d } \\
\text { (Median } 1\end{array}$ & $\begin{array}{l}\text { e rang } \\
/ 1 / 198\end{array}$ & * & $1 / 99$ & & $\begin{array}{l}\text { Incident date } \\
\text { (Median } 8 / 1 / 8\end{array}$ & $\begin{array}{l}\text { range } 1 / 1 / 1 \\
89)^{*}\end{array}$ & 919-1/1 & 2000 \\
\hline Low & & 5697 & $22 \%$ & & Low & 4553 & & $20 \%$ \\
\hline Moderate & & 6121 & $23 \%$ & & Moderate & 5212 & & $22 \%$ \\
\hline Severe & & 5219 & $20 \%$ & & Severe & 4590 & & $20 \%$ \\
\hline Death & & 9089 & $35 \%$ & & Death & 8864 & & $38 \%$ \\
\hline Neglige & $(N=59$ & $1(23 \%))$ & Not neglige & nt $(\mathrm{N}=13$ & $13683(52 \%)$ & Other & $\overrightarrow{\mathrm{N}}=652$ & $(25 \%))$ \\
\hline $\begin{array}{l}\text { Payn } \\
(\mathrm{N}=\end{array}$ & $\begin{array}{l}\text { int to cl } \\
5088(8\end{array}$ & $\begin{array}{l}\operatorname{mant} \\
\%) \delta \S\end{array}$ & $\begin{array}{r}\text { Paym } \\
\text { (N }\end{array}$ & $\begin{array}{l}\text { ent to clo } \\
=915(79\end{array}$ & $\begin{array}{l}\text { laimant } \\
7 \%)) \S\end{array}$ & $\begin{array}{l}\text { Paym } \\
(\mathrm{N}=\end{array}$ & $\begin{array}{l}\text { ent to clo } \\
1848(28\end{array}$ & $\begin{array}{l}\text { nant } \\
\text { 6))ई }\end{array}$ \\
\hline Low & 921 & $18 \%$ & Low & 151 & $17 \%$ & Low & 285 & $15 \%$ \\
\hline Moderate & 1327 & $26 \%$ & Moderate & 201 & $22 \%$ & Moderate & 445 & $24 \%$ \\
\hline Severe & 980 & $19 \%$ & Severe & 239 & $26 \%$ & Severe & 500 & $27 \%$ \\
\hline Death & 1860 & $37 \%$ & Death & 324 & $35 \%$ & Death & 618 & $34 \%$ \\
\hline Total & 5088 & $100 \%$ & Total & 915 & $100 \%$ & Total & 1848 & $100 \%$ \\
\hline & $\begin{array}{l}\text { payme } \\
833(1\end{array}$ & & $(N=$ & $\begin{array}{l}\text { o payme } \\
12768 \text { (S }\end{array}$ & $\begin{array}{l}\text { ent } \\
(93 \%))\end{array}$ & & $\begin{array}{l}\text { o paym } \\
4674(\end{array}$ & \\
\hline Low & 186 & $22 \%$ & Low & 3082 & $24 \%$ & Low & 1072 & $23 \%$ \\
\hline Moderate & 215 & $26 \%$ & Moderate & 2944 & $23 \%$ & Moderate & 989 & $21 \%$ \\
\hline Severe & 144 & $17 \%$ & Severe & 2380 & $19 \%$ & Severe & 976 & $21 \%$ \\
\hline Death & 288 & $35 \%$ & Death & 4362 & $34 \%$ & Death & 1637 & $35 \%$ \\
\hline Total & 833 & $100 \%$ & Total & 12768 & $100 \%$ & Total & 4674 & $100 \%$ \\
\hline
\end{tabular}

Figure 1 Primary care malpractice claims relative to peer review. 


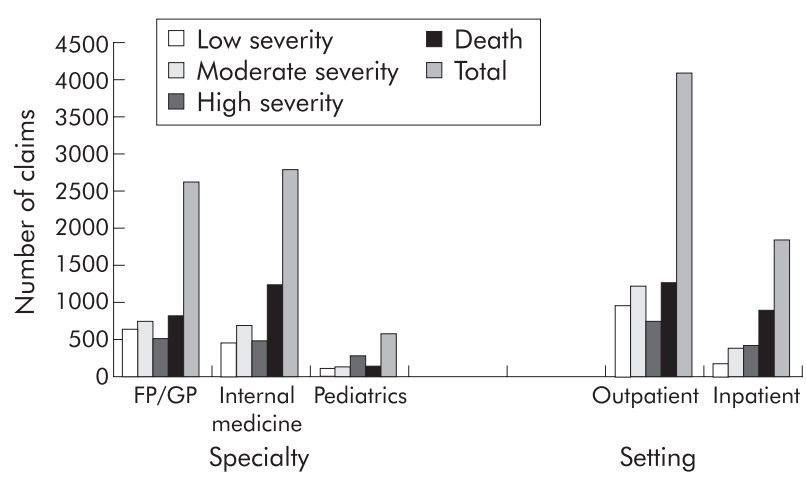

Figure 2 Volume and severity of negligent malpractice claims by specialty and setting; $F P / G P=$ family practice/general practice physician.

table 1). In contrast, $77 \%$ of claims held only five underlying causes, the most prominent being "diagnostic error" (34\%, table 1).

\section{Contributing factors}

Many contributing factors, such as "vicarious liability", were not useful for understanding threats to patient safety; however, "communication between providers" and "premature discharge from institution" provide insight into factors facilitating harm. "Problems with records", for example, was listed as contributing to 439 claims and 156 deaths (table 2).

\section{Relative risk}

Creating a rate ratio of proportion of claims and proportion of office visits for specific conditions revealed wide variance in the relative risk for error related claims associated with different medical conditions. To exemplify this we chose the 10 most prevalent conditions with error related claims. For example, appendicitis is a relatively rare reason for encounter reported in NAMCS $(0.003 \%)$ but is more common for negligent adverse events in the claims data (1.6\%). The ratio of these proportions (claims/office visits) is 519.94 . This risk ratio is 25 times that of breast cancer (table 3). Even within cancer types there was twofold variation in risk for colon and lung cancer compared with breast cancer despite similar volumes of primary care office visits.

\section{DISCUSSION}

Our study identifies conditions and processes where primary health care in the US may be prone to go awry. Claims for negligent adverse events involving primary care physicians occurred more often in outpatient settings than in hospitals where many US primary care physicians provide care. While negligent adverse events were significantly more likely to have severe outcomes when they occurred in hospitals, the total burden of high severity outcomes and death was larger in the outpatient setting. Acute myocardial infarction and cancer were prominent in negligent claims, probably due in part to their prevalence as major causes of morbidity and mortality in the US. However, no single condition accounted for more than $5 \%$ of all negligent claims. Distribution of claims among the 18 categories of underlying cause was much more clustered-three out of four claims occurred in five categories-and diagnostic error alone accounted for over one third of claims.

The PIAA data also identified contributing factors that suggest system problems in primary care that need improving. "Problems with records" had a fairly even distribution across the outcome severity categories while "communication between providers" was skewed more towards high severity outcomes and death. Both suggest that frequent errors in primary care, often thought to be trivial, can contribute to bad health outcomes for patients and should not be ignored. ${ }^{56}$

The malpractice databases used in this analysis offer valuable insights into the conditions, causes, contributing issues, and severity of errors. However, we also found that analyzing these data with other public datasets adds to the understanding of medical errors. NAMCS data allowed us to explore the relative risk of negligent events for specific medical conditions becoming a claim in primary care. The extension of relative risk evaluations could be further dissected to evaluate sex specific risks (such as breast cancer compared with other women's health issues) or other specific characteristics of patients, providers, and settings. These are risks of claim-not risk of error-but, as a measure of patient recognized negligent events in the course of their care, these relative risks reveal outlying conditions that may be priorities for improving care and reducing costs.

A weakness of this study is that the "contributing factor" variable is not more robust. This variable is secondary for risk management analyses. Malpractice data might be more useful for patient safety purposes if these factors were more consistently captured and if the categories were drawn from those recommended by Reason, ${ }^{20}$ Vincent, ${ }^{21}$ and others. This study has other limitations. Malpractice data provide a limited view of patients' experiences with errors and adverse outcomes. Previous studies have raised the concern that most physician negligence never leads to malpractice claims, and most claims are not the result of negligence. ${ }^{22}$ As in a related study, we have focused on the claims judged to arise from negligent events. ${ }^{12}$ The fact that claim volume was not proportional to the volume of care provided in each setting may reflect a lower level of overall severity for both patient health status and outcomes in the outpatient setting, and

\begin{tabular}{lc}
$\begin{array}{l}\text { Table } 1 \text { Most common diagnoses and } \\
\text { underlying causes associated with negligent } \\
\text { claims (total 5921) }\end{array}$ \\
\hline $\begin{array}{l}\text { Error (indefensible) } \\
\text { No (\%) }\end{array}$ \\
\hline $\begin{array}{l}\text { Disease or injury category } \\
\text { Acute myocardial infarction }\end{array}$ & $269(5)$ \\
Lung cancer & $166(3)$ \\
Breast cancer & $147(3)$ \\
Colon cancer & $145(3)$ \\
Brain damaged infant & $115(2)$ \\
Appendicitis & $95(2)$ \\
Meningitis & $80(1)$ \\
Pulmonary embolism & $79(1)$ \\
Diabetes & $72(1)$ \\
Symptoms involving abdomen & $71(1)$ \\
and pelvis & $4682(79)$ \\
Other & \\
Underlying cause & $2003(34)$ \\
Diagnosis error & $972(16)$ \\
Failure to supervise or monitor \\
case
\end{tabular}


Table 2 Contributing factors associated with primary care negligent claims by severity

\begin{tabular}{|c|c|c|c|c|c|}
\hline Associated issue & Low severity & $\begin{array}{l}\text { Moderate } \\
\text { severity }\end{array}$ & $\begin{array}{l}\text { High } \\
\text { severity }\end{array}$ & Death & $\begin{array}{l}\text { Total }(\%) \text { of } \\
\text { negligent claims }\end{array}$ \\
\hline Problems with records & $57(13 \%)$ & $131(30 \%)$ & $95(22 \%)$ & $156(36 \%)$ & $439(7 \%)$ \\
\hline Consent issues, breach of contract & 61 (26\%) & $110(48 \%)$ & $22(10 \%)$ & $38(16 \%)$ & $231(4 \%)$ \\
\hline $\begin{array}{l}\text { Premature discharge from } \\
\text { institution }\end{array}$ & $16(9 \%)$ & $37(20 \%)$ & $28(15 \%)$ & 103 (56\%) & $184(3 \%)$ \\
\hline$x$ ray error & $24(15 \%)$ & $42(26 \%)$ & $30(18 \%)$ & $68(41 \%)$ & $164(3 \%)$ \\
\hline Vicarious liability & $34(26 \%)$ & $31(23 \%)$ & 30 (23\%) & $37(28 \%)$ & $132(2 \%)$ \\
\hline $\begin{array}{l}\text { Communication between } \\
\text { providers }\end{array}$ & $16(12 \%)$ & $16(12 \%)$ & $27(21 \%)$ & $72(55 \%)$ & $131(2 \%)$ \\
\hline Other & 796 (19\%) & $1039(25 \%)$ & 779 (19\%) & $1485(36 \%)$ & 4103 (70\%) \\
\hline Total & 1097 (19\%) & $1531(26 \%)$ & $1115(19) \%$ & $2138(36 \%)$ & 5881 (100\%) \\
\hline
\end{tabular}

perhaps an operating bias for more severe outcomes to become claims. Furthermore, the number of claims according to the specialty of primary care physicians cannot be denominated since PIAA does not collect physician exposure data. Whether review panel judgments are reliable or valid for assessing medical negligence is still a matter of debate. $^{822} 23$ Assignment of underlying causes, while standardized and rigorous, may have too few categorical options for use in patient safety research. Johnson ${ }^{24}$ refers to this as "recognition bias" - that is, that the choices for categorizing events is limited and reviewers "fit" incidents to available factors "irrespective of the complexity of the circumstances". Another potential limitation is that assignment of an underlying cause may not reflect true root causes, with the risk of producing interventions that do not avert bad outcomes. There are also potential biases arising from how lucrative certain diagnoses are when a bad outcome occurs that may influence the prevalence, the relative severity, or the resolution of claims. An important limitation of our analyses is the inability to calculate standard errors or confidence intervals for the relative risk assessments. This is related to the fact that the US National Center for Health Statistics has not yet provided standard errors for NAMCS conducted before 1993. Given that standard errors for subsequent NAMCS (also included in our aggregate data) were exceedingly small, we felt the importance of using weighted clinical data reflective of the same time period as the claims data negated this limitation. As the NCHS retrospectively provides the standard errors for the earlier NAMCS, we hope to be able to correct this limitation.

Limitations notwithstanding, the PIAA data sharing project database of settled suits and claims is a rich resource for studying patient safety in primary care settings. These data reveal that many errors occur in primary care and the outpatient care setting and are a significant source of morbidity and mortality. These malpractice data, when combined with other data, can reveal conditions for which claims are disproportionate to volume of care, potentially offering a scheme for prioritizing patient safety research and policy agendas for primary care. Finally, these data reveal associated or contributing issues, many suggesting system level factors that may be important for averting errors and adverse events.

\section{Implications for research and policy}

The prevailing focus for patient safety research and policy to date has been care delivered in hospitals or other inpatient settings. ${ }^{525-28}$ While hospitals have demonstrated threats to patient safety, they are also the least frequently used component of the American health system. ${ }^{29}$ The overwhelming majority of health care in the US is delivered outside of hospitals. ${ }^{30}$ There were 25 times more office visits to office based physicians than to hospitals in 2000 (824 million $v 32$ million). ${ }^{31}{ }^{32}$ The volume and increasing complexity of primary care and the potential for relatively

\begin{tabular}{|c|c|c|c|c|c|}
\hline \multirow[b]{2}{*}{$\begin{array}{l}\text { Disease or injury } \\
\text { category }\end{array}$} & \multicolumn{2}{|c|}{ Error (indefensible) } & \multicolumn{2}{|c|}{$\begin{array}{l}\text { Office visits to primary care for this } \\
\text { condition }\end{array}$} & \multirow{2}{*}{$\begin{array}{l}\text { Relative risk } \\
\begin{array}{l}\text { Proportion of error } \\
\text { claims/proportion } \\
\text { office visits }\end{array}\end{array}$} \\
\hline & No & $\begin{array}{l}\text { Proportion of } \\
\text { all error claims* }\end{array}$ & $\begin{array}{l}\text { Weighted office } \\
\text { visits }\end{array}$ & $\begin{array}{l}\text { Proportion of all } \\
\text { office visits }^{\star *}\end{array}$ & \\
\hline $\begin{array}{l}\text { Acute myocardial } \\
\text { infarction }\end{array}$ & 269 & 0.045432 & 3248893 & 0.000626003 & 72.57 \\
\hline Lung cancer & 166 & 0.028036 & 3580812 & 0.000689957 & 40.63 \\
\hline Breast cancer & 147 & 0.024827 & 6780949 & 0.001306566 & 19.00 \\
\hline Colon cancer & 145 & 0.024489 & 3346139 & 0.00064474 & 37.98 \\
\hline Brain damaged infant & 115 & 0.019422 & 102915 & $1.98298 \mathrm{E}-05$ & 979.45 \\
\hline Appendicitis & 95 & 0.016045 & 160152 & $3.08584 \mathrm{E}-05$ & 519.94 \\
\hline Meningitis & 80 & 0.013511 & 2399513 & 0.000462343 & 29.22 \\
\hline Pulmonary embolism & 79 & 0.013342 & 1938023 & 0.000373422 & 35.73 \\
\hline Diabetes & 72 & 0.01216 & 149593203 & 0.028823889 & 0.42 \\
\hline $\begin{array}{l}\text { Symptoms involving } \\
\text { abdomen and pelvis }\end{array}$ & 71 & 0.011991 & 8172013 & 0.001574598 & 7.62 \\
\hline \multicolumn{6}{|c|}{$\begin{array}{l}\text { *Denominated by } 5921 \text { error claims. } \\
\text { **Denominated by } 5189903572 \text { office visits for all conditions (weighted), 1980-1999. } \\
\text { A relative risk of }>1 \text { means that it appears in error related claims relatively more often than patient office visits; a } \\
\text { relative risk of }<1 \text { means that it appears in error related claims relatively less often than patient office visits; a } \\
\text { relative risk of } 1 \text { means that error related claims and office visits are the same. }\end{array}$} \\
\hline
\end{tabular}




\section{Key messages}

- Similar medical negligence principles and problems occur in the US and the UK.

- Malpractice claims data reveal a patient centred view of the burden of harm, costs, and potential protections from medical negligence.

- For US primary care physicians, negligent adverse events more offen occur outside of hospitals, are dominated by diagnostic errors, and tell us most about potential priority conditions when combined with clinical data.

- The value of claims data for improving patient safety would be enhanced by better discernment of root causes of negligent adverse events, more complete peer review and determination of negligence, and collecting more complete data about systems failures that contribute to medical negligence.

frequent systematic errors make investigation of errors in primary care critically important. ${ }^{13533}$ Our findings help describe the scope of patients' experiences with negligent adverse events in primary care, and offer potential targets for prioritized research or intervention. These targets include refining the taxonomy of factors that cause or facilitate errors. Our analyses also suggest that even "trivial", frequent, error related occurrences contribute to severe outcomes. Patients are affected frequently by "problems with records" and failed "communication between providers", but these are not typically thought of as important threats to patient safety. Consistent with recent events, we found that these and other system failures have tragic effects when they align with other errors. ${ }^{19}{ }^{33} 34$ More complete characterization in malpractice claims data of system failures that contribute to negligent adverse events may be one of the richest opportunities for future research and efforts to help good doctors prevent lapses in care.

\section{ACKNOWLEDGMENTS}

The authors thank Katrina Miller for early data management, Donald Pathman for his comments and critiques, and Lisa Klein for her help with manuscript preparation.

\section{Authors' affiliations}

R L Phillips Jr, S M Dovey, G E Fryer Jr, L A Green, The Robert Graham Center: Policy Studies in Family Practice and Primary Care, Washington, DC 20036, USA

L A Bartholomew, Loss Prevention and Research, Physician Insurers Association of America, Rockville, MD 20850, USA

T J Miyoshi, University of Colorado Department of Family Medicine, Denver, CO 80262, USA

Conflict of interest: $\mathrm{BH}$ is a member of the doctors group of the Association of Victims of Medical Accidents (AVMA).

The research reported in this paper was conducted in the Robert Graham Center: Policy Studies in Family Practice and Primary Care, American Academy of Family Physicians. The information and opinions contained in research from The Graham Center do not necessarily reflect the views or policy of The American Academy of Family Physicians.

Supported by The Robert Graham Center: Policy Studies in Family Practice and Primary Care, and The Physician Insurers Association of America (data and writing, not financial).

\section{REFERENCES}

1 Hammons T, Piland NF, Small SD, et al. An agenda for research in ambulatory patient safety. Synthesis of a multidisciplinary conference, 2001.

2 National Patient Safety Foundation. Agenda for research and development in patient safety. National Patient Safety Foundation, 1999:1-12.

3 Department of Health. An organization with a memory. Report of an expert group on learning from adverse events in the NHS chaired by the Chief Medical Officer. London: The Stationery Office, 2000.

4 Rubin G. Medical errors: terminology of "error" is important. BMJ 2001;322:1422.

5 Dovey S, Meyers D, Phillips R, et al. A taxonomy of medical errors in family practice. Qual Saf Health Care 2002;11:233-8.

6 Dovey SM, Phillips RL, Green LA. Medical errors affecting vulnerable primary care patients in six countries. A report of the Linnaeus Collaboration. Academy for Health Services Research and Health Policy Annual Research Meeting, Health Services Research From Knowledge to Action. Washington, DC, 2002.

7 Makeham MAB, Dovey SM, County M, et al. An international taxonomy for errors in general practice: a pilot study. Med J Aust 2002;177:68-72.

8 Thomas E, Studdert D, Burstin H, et al. Incidence and types of adverse events and negligent care in Utah and Colorado. Med Care 2000;38:261-71.

9 Elder N, Dovey S. Classification of medical errors and preventable adverse events in primary care: a synthesis of the literature. J Fam Pract 2002;51:927-32.

10 Thomas E, Brennan T. Incidence and types of preventable adverse events in elderly patients: population based review of medical records. BMJ 2000:320:741-4.

11 Meredith M, Cook C, Penman A. Use of the Physician Insurers' Association of America database as a surveillance tool for diabetes-related malpractice claims in the U.S. Diabetes Care 1998;21:1096-100.

12 Kravitz RL, Rolph JE, McGuigan K. Malpractice claims data as a quality improvement tool. I: Epidemiology of error in four specialties. JAMA 1991;266:2087-92.

13 Rothschild JM, Frank F, Gandhi TK, et al. Analysis of medication related malpractice claims: causes, preventability, and costs. Arch Intern Med 2002;162:2414-20.

14 Maughan PJ. Medical negligence and the law. Br J Surg 2001;88:899-900.

15 US Department of Health and Human Services Health Resources and Services Administration. National Practitioner Data Bank 2000: Annual Report. Rockville, MD: Department of Health and Human Services, 2000.

16 Fenn P. Counting the cost of medical negligence: NHS litigation authority will be able to report on costs and high risk procedures. BMJ 2002;325:233-4.

17 Vincent C, Young M, Phillips A. Why do people sue doctors? A study of patients and relatives taking legal action. Lancet 2003;343:1609-13.

18 Physician Insurers Association of America. Data sharing project information manual. 2001

19 Mechanic D, McAlpine DD, Rosenthal M. Are patients' office visits with physicians getting shorter? N Engl J Med 2001;344:198-204.

20 Reason J. Human error: models and management. BMJ 2000;320:768-70.

21 Vincent C. Understanding and responding to adverse events. N Engl J Med 2003;348:1051-6.

22 Report of the Harvard Medical Practice Study to the State of New York. Patients, doctors, and lawyers: medical injury, malpractice litigation, and patient compensation in New York. Cambridge, Mass: Harvard University Press, 1990.

23 Hayward RA, Hofer TP. Estimating hospital deaths due to medical errors: preventability is in the eye of the reviewer. JAMA 2001;286:415-20.

24 Johnson CW. Reasons for the failure of incident reporting in the healthcare and rail industries. In: Redmill F, Anderson T, eds. Components of system safety: Proceedings of the 10th Safety Critical Systems Symposium. Berlin: Springer Verlag, 2001:31-60

25 Kohn LT, Corrigan JM, Donaldson MS. To err is human: building a safer health system. Washington, DC: National Academy Press, 2002.

26 Fetters MD. Medical error in primary care. In: Rosenthal MM, Sutcliffe KM, eds. Medical error: What do we know? What do we do? San Francisco: Jossey-Bass, 2002:58-83.

27 National Quality Forum Current Activities and Consensus Reports. The National Forum for Health Care Quality Measurement and Reporting. The National Forum for Health Care Quality Measurement and Reporting. http:// www.qualityforum.org/news/gfacrnew2.htm (accessed 12 March 2003).

28 Center for Medicare and Medicaid Services. Secretary Thompson welcomes new effort to provide hospital quality of care information. Center for Medicare and Medicaid Services. http://www.hhs.gov/news/press/2002pres/ 20021212.html (accessed 12 April 2003).

29 White KL, Williams TF, Greenberg BG. The ecology of medical care. N Engl J Med 1961;265:885-92.

30 Green LA, Fryer GE, Yawn B, et al. The ecology of medical care revisited. N Engl J Med 2001;344:2021-5.

31 National Center for Health Statistics. Office visits to physicians. http:// www.cdc.gov/nchs/fastats/docvisit.htm (accessed 12 April 2003).

32 National Center for Health Statistics. Hospital utilization. http:// www.cdc.gov/nchs/fastats/hospital.htm (accessed 12 April 2003).

33 Dovey SM, Fryer GE, Green L, et al. Toxic cascades. A comprehensive way to think about medical errors. Am Fam Physician 2001;63:847.

34 Anon. Lessons from Jesica. Inside Duke University Medical Center \& Health System 2003;12. 